\title{
Development, Translation and Validation of Enhanced Asian Rome III Questionnaires for Diagnosis of Functional Bowel Diseases in Major Asian Languages: A Rome Foundation-Asian Neurogastroenterology and Motility Association Working Team Report
}

\begin{abstract}
Uday C Ghoshal, ${ }^{1}$ Kok-Ann Gwee, ${ }^{2 *}$ Minhu Chen, ${ }^{3}$ Xiao R Gong, ${ }^{2,3}$ Nitesh Pratap, ${ }^{4}$ Xiaohua Hou, ${ }^{5}$ Ari F Syam, ${ }^{6}$ Murdani Abdullah, ${ }^{6}$ Young-Tae Bak, ${ }^{7}$ Myung-Gyu Choi, ${ }^{8}$ Sutep Gonlachanvit, ${ }^{9}$ Andrew S B Chua, ${ }^{10}$ Kuck-Meng Chong, ${ }^{11}$ Kewin T H Siah, ${ }^{12}$ Ching-Liang Lu, ${ }^{13}$ Lishou Xiong ${ }^{3}$, and William E Whitehead ${ }^{14}$

${ }^{1}$ Department of Gastroenterology, Sanjay Gandhi Postgraduate Institute of Medical Sciences, Lucknow, India; ${ }^{2}$ Department of Medicine, Yong Loo Lin School of Medicine, National University of Singapore, Singapore; ${ }^{3}$ Department of Gastroenterology and Hepatology, The First Affiliated Hospital, Sun Yat-Sen University, Guangzhou, Guangdong, China; ${ }^{4}$ Asian Institute of Gastroenterology, Hyderabad, India; ${ }^{5}$ Department of Gastroenterology and Hepatology, Union Hospital of Tongji Medical College, Huazhong University of Science and Techonology, Wuhan, Hubei, China; ${ }^{6}$ Division of Gastroenterology, Department of Internal Medicine, Cipto Mangunkusumo General Hospital/Faculty of Medicine, University of Indonesia, Jakarta, Indonesia; ' Department of Gastroenterology, Korea University Guro Hospital, Seoul, South Korea; ${ }^{8}$ Division of Gastroenterology, Department of Internal Medicine, Seoul St. Mary's Hospital, The Catholic University of Korea, Seoul, Korea; ${ }^{9}$ GI Motility Research Unit, Division of Gastroenterology, Department of Medicine, Faculty of Medicine, Chulalongkorn University, Bangkok,

Thailand; ${ }^{10}$ Gastro Centre Ipoh, Ipoh, Perak, Malaysia; ${ }^{11}$ Klinic Chong, Slim River, Perak, Malaysia, ${ }^{12}$ Division of Gastroenterology \& Hepatology, University Medicine Cluster, National University Hospital, Singapore; ${ }^{13}$ Division of Gastroenterology, Taipei Veterans General Hospital, National Yang-Ming University Taipei, Taiwan; and ${ }^{14}$ Center for Functional GI and Motility Disorders, University of North Carolina at Chapel Hill, Chapel Hill, NC, USA
\end{abstract}

Received: April 10, 2014 Revised: October 6, 2014 Accepted: October 8, 2014

(c) This is an Open Access article distributed under the terms of the Creative Commons Attribution Non-Commercial License (http://creativecommons. org/licenses/by-nc/3.0) which permits unrestricted non-commercial use, distribution, and reproduction in any medium, provided the original work is properly cited.

*Correspondence: Kok-Ann Gwee, FRCP, PhD

Stomach, Liver and Bowel Center, Gleneagles Hospital, Annexe Block 05-37, 6A Napier Road, Singapore 258500, Singapore Tel: +65-6474-6848, Fax: +65-6475-8285, E-mail: slbclinic@gmail.com

Financial support: Authors thank Abbott and Janssen Pharmaceutical for unconditional financial support towards the activities of the study through Asian Neurogastroenterology and Motility Association. This work is supported by Rome Foundation (http://www.romecriteria.org), USA and Asian Neurogastroenterology and Motility Association (www.asianmotility.org).

Conflicts of interest: Kok-Ann Gwee has received research grants from Abbott Laboratories and Janssen Pharmaceuticals, speaking honorarium from Abbott Laboratories, Janssen Pharmaceuticals and Boehringer Ingelheim International $\mathrm{GmbH}$, and is on the scientific advisory board of Danone Research. The other authors have no conflict of interest to declare.

Author contributions: Uday C Ghoshal, study conceptualisation, planning, supervision, data analysis, and manuscript writing; Kok-Ann Gwe, study conceptualisation, planning, and manuscript writing; Sutep Gonlachanvit, Minhu Chen, Nitesh Pratap, Xiao R Gong, Xiaohua Hou, Ari F Syam, Murdani Abdullah, Young-Tae Bak, Myung-Gyu Choi, Andrew S B Chua, Kuck-Meng Chong, Kewin T H Siah, Ching-Liang Lu and Lishou Xiong, planning, supervision, data analysis, and manuscript review; William E Whitehead, study conceptualization, and planning of the manuscript.

ORCID: Uday C Ghoshal, http://orcid.org/0000-0003-0221-8495. 


\begin{abstract}
Background/Aims
The development-processes by regional socio-cultural adaptation of an Enhanced Asian Rome III questionnaire (EAR3Q), a cultural adaptation of the Rome III diagnostic questionnaire (R3DQ), and its translation-validation in Asian languages are presented. As English is not the first language for most Asians, translation-validation of EAR3Q is essential. Hence, we aimed to culturally adapt the R3DQ to develop EAR3Q and linguistically validate it to show that the EAR3Q is able to allocate diagnosis according to Rome III criteria.
\end{abstract}

\title{
Methods
}

After EAR3Q was developed by Asian experts by consensus, it was translated into Chinese, Hindi-Telugu, Indonesian, Korean, and Thai, following Rome Foundation guidelines; these were then validated on native subjects (healthy $[n=60]$, and patients with irritable bowel syndrome [ $n=59]$, functional dyspepsia $[n=53]$ and functional constipation $[n=61])$ diagnosed by clinicians using Rome III criteria, negative alarm features and investigations.

\section{Results}

Experts noted words for constipation, bloating, fullness and heartburn, posed difficulty. The English back-translated questionnaires demonstrated concordance with the original EAR3Q. Sensitivity and specificity of the questionnaires were high enough to diagnose respective functional gastrointestinal disorders (gold standard: clinical diagnoses) in most except Korean and Indonesian languages. Questionnaires often uncovered overlapping functional gastrointestinal disorders. Test-retest agreement (kappa) values of the translated questionnaires were high (0.700-1.000) except in Korean (0.300-0.500) and Indonesian (0.100-0.400) languages at the initial and 2-week follow-up visit.

\section{Conclusions}

Though Chinese, Hindi and Telugu translations were performed well, Korean and Indonesian versions were not. Questionnaires often uncovered overlapping FGIDs, which were quite common.

(J Neurogastroenterol Motil 2015;21:83-92)

\section{Key Words}

Asia; Gastrointestinal diseases; Rome III criteria; Translations; Validation

\section{Introduction}

The functional gastrointestinal disorders (FGIDs) are comprised of a group of conditions that are currently defined by the presence of certain symptoms attributable to the gastrointestinal (GI) tract, in the absence of organic causes identifiable by routine investigations. ${ }^{1}$ To harmonize research in this field, a framework known as the Rome Criteria was developed to attempt classification of patients into diagnostic labels based putatively on the sites of the GI tract and the pathophysiological disturbances implicated. ${ }^{2}$

However, these symptom-based diagnostic criteria, though led to substantial progress in research and care of patients with FGIDs, have limitations as there is lack of uniformity in socio-cultural issues, languages, symptom reporting and spectrum of FGIDs across the world. ${ }^{3}$ Moreover, these criteria and questionnaires were written in English in the first iteration, and subsequently translated into other languages. However, the nuances of some English wording may not be appreciated by non-English speakers and conversely, some regional terms may not have equivalent English word. As the identification and classification of FGIDs are dependent entirely on the ability of patients to describe and of the clinicians and investigators to interpret symptoms, we wonder if these criteria would do well in diagnostic allocation, sub-typing and treatment assignment uniformly throughout the world. ${ }^{4}$

In epidemiologic, pathophysiologic and therapeutic studies of FGIDs, the Rome Criteria have been applied almost universally. Epidemiological studies from Asia suggest that the prevalence and spectrum of FGIDs may differ in Asia compared to the West. ${ }^{3,5-12}$ There is growing interest to evaluate this issue in a more systematic manner in multi-national cross-cultural studies. ${ }^{13-15}$ One of the barriers to such studies relates to the lack of a culturally adapted international questionnaire that has been translated and validated in various Asian languages using standard methods. ${ }^{16}$ As FGIDs are diagnosed by symptoms-based criteria, ${ }^{17,18}$ which are subject to psychosocial and socio-cultural influences, ${ }^{7,19,20}$ it is 
important that the terminologies used in the questionnaire are culturally adapted, so that the patients can understand their meanings clearly. ${ }^{13,14,21,22}$ Accordingly, we undertook a study with the following aims: (1) to develop a socio-culturally adapted questionnaire based on the Rome III diagnostic questionnaire (R3DQ), ${ }^{23}$ (2) to translate it into various Asian languages according to the Rome Foundation guidelines, ${ }^{24}$ and (3) linguistic validation of the translated questionnaire to demonstrate that the various Asian translations of the Enhanced Asian Rome III questionnaire (EAR3Q) were able to allocate diagnosis according to the Rome III criteria.

\section{Materials and Methods}

\section{The Study Protocol}

This was a 3-phase prospective study involving experts with recent publications on FGIDs from 9 countries, mostly from Asia (2 of which are English-speaking, namely Singapore and USA). The organization of this study is presented in Figure. In the third phase of the study, the translated questionnaire has been field tested in a pan-Asian survey. However, in this report, we present the findings from phase 1 and 2 of this study. The findings of the Asian FGID Study will be presented in separate manuscripts.

\section{Phase 1: Development of Enhanced Asian Rome III Questionnaire From Rome III Diagnostic Questionnaire}

These experts were tasked to evaluate the translatability of the R3DQ to the languages of their country. Specifically, we sought to identify questions that posed difficulty for patients to understand the nuances pertaining to their English expression. The experts were encouraged to conduct cognitive interviews with their patients to understand how the relevant questions were interpreted.

The working groups were organized according to the way the R3DQ was divided into anatomical sections, ie, esophagus, stomach and intestines, gallbladder or pancreas and rectum or anal canal. The working groups were tasked to examine the adequacy of the questions to describe the Asian person's pattern of symptom reporting for the sections they were assigned. At a round-table meeting, the experts presented their findings. The R3DQ was reviewed question by question. For the questions that were identified to be difficult for an Asian patient to understand, new ques- tions were developed taking account of socio-cultural factors and encompassing the nuances of Asian languages. New questions were also developed for symptoms where it was found that existing questions were inadequate for describing Asian patients' and physicians' clinical encounters. In the new questions we used neutral terms to describe patients' symptom experiences, as much as possible. The new questions will be referred to as Asian adapted questions. To maintain compatibility with the R3DQ and to allow for comparison with earlier studies, we retained all the original questions in their original wording, but positioned the Asian adapted questions directly after each of the original question. The combination of the R3DQ with the Asian adapted questions was named the EAR3Q, which is presented in the Supplementary Table 1.

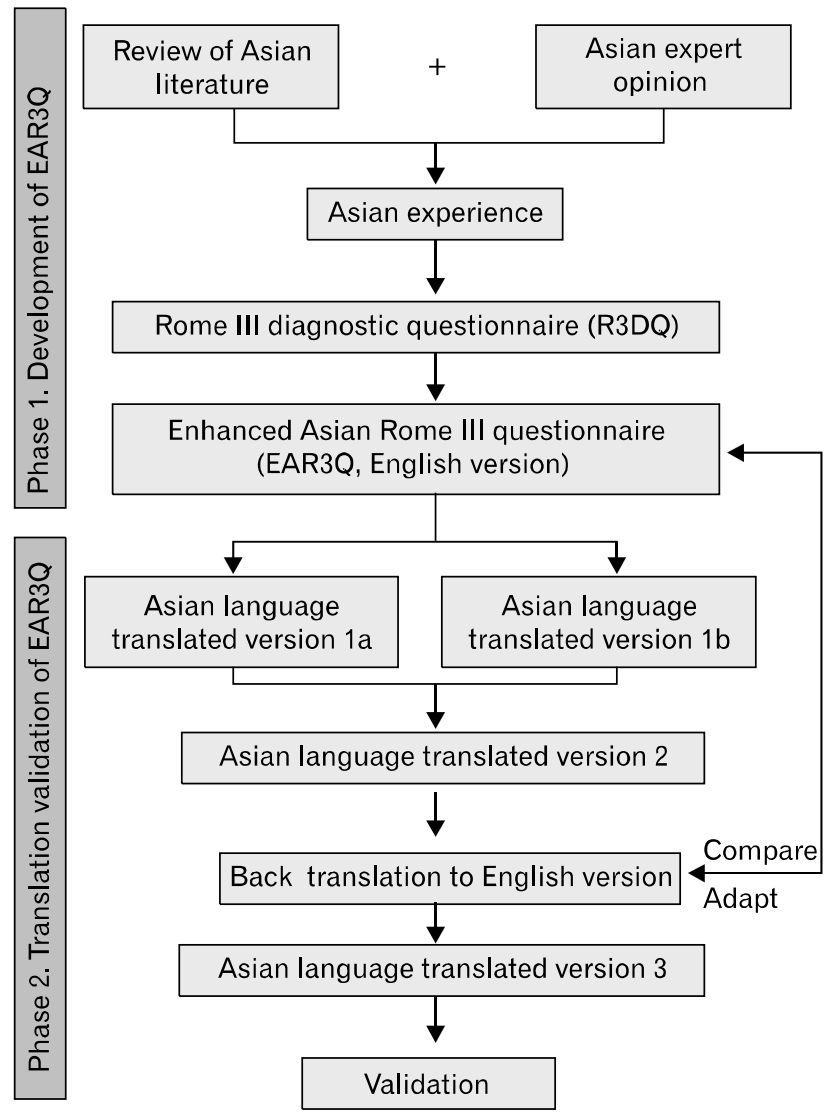

Figure. Outline of the process of development of Enhanced Asian Rome III questionnaire (EAR3Q) from Rome III diagnostic questionnaire (R3DQ) and its translation and validation in different Asian languages. 


\section{Phase 2: Translation-Validation of Enhanced Asian Rome III Questionnaire Into Various Languages}

From January to December 2011, The EAR3Q was translated into the following languages: Chinese, 2 Indian (Hindi and Telugu), Indonesian, Korean, and Thai. These translations were then tested on a prospective sample of patients speaking these languages and suffering from irritable bowel syndrome (IBS), functional dyspepsia (FD) and functional constipation (FC), as well as native healthy subjects (HS). Translation-validation was conducted according to the Rome Foundation guidelines for new language translations. ${ }^{21}$

\section{The process of translation of the Enhanced Asian Rome III questionnaire}

EAR3Q was translated into each language by 2 independent translators separately (Asian versions $1 \mathrm{a}$ and 1b, Figure). Subsequently, the 2 versions were reconciled by another expert wellconversant in the respective language to create a final translated questionnaire (Asian version 2), which was back translated into English by another qualified expert well-conversant in both languages. The original and the backward English versions of the questionnaire were assessed for similarity of language and comparability of interpretation, and where necessary, revisions and modifications were made to the Asian version to produce Asian version 3. The final Asian versions 3 in different languages are in Supplementary Tables 2-7.

\section{Validation of the translated questionnaires}

After the process of translation as described above, the questionnaires were validated on the HS and patients with IBS, FD, and FC (diagnosed by clinicians using Rome III criteria as in practice setting, by symptoms, negative alarm features ${ }^{17,18}$ with exclusion of organic disease with appropriate investigations, which is considered as the gold standard) belonging to respective nations and speaking respective language as their native language. The diagnosis of each group of patients with FGID was made initially by the clinician as he/she would do in his/her clinical practice by interview using the Rome III criteria, and investigating alarm features where these were present. Subsequently, the patients were asked to fill in the translated questionnaire. Each subject was asked to fill in the questionnaire himself/herself. However, in most centres, a research assistant sat with the subject at the time of filling the questionnaire. Exclusion criteria of patients included presence of alarm symptoms, the cause for which had not been verified with appropriate investigations. After a 2-week period, subjects were asked to repeat the questionnaire to check for its reproducibility. Supplemental questions, as detailed in Supplementary Table 1, were not included when questionnaire-based diagnoses were compared to the clinical diagnoses. The study protocol was approved by the Ethics Committee of the respective Institutes. Informed consent was obtained from each subject.

\section{Statistical Methods}

The categorical and continuous data are presented as proportion, median and range, respectively. We assessed the validity of the questionnaire by examining its sensitivity to pick-up clinicians' diagnoses (considered as gold standard) at the initial visit. If the questionnaire picked-up the diagnoses made by the clinician, the result was considered true positive and if not, it was considered false negative. For calculation of specificity, the proportion of healthy subjects labelled as healthy was considered. The test-retest reliability analysis involved re-testing subjects after 2 weeks. The agreement between diagnoses made at different time points by the questionnaire was evaluated by kappa statistics. Values for kappa $>0.810$ were considered excellent agreement, between $0.610-0.800$ as good agreement and those below < 0.600 as poor agreement.

Results

\section{Phase 1: Results of Study on Development of Enhanced Asian Rome III Questionnaire From Rome III Diagnostic Questionnaire}

While evaluating the translatability of questions in the English version of the R3DQ, to the language of their country, the experts identified difficulty with the questions on globus, dysphagia, odynophagia, anal blockage and digital manoeuvres. These questions together with the reasons for difficulty and the adapted questions that we propose are presented in the Supplementary Table 8 as R3DQ Q No. 3, 4, 56, and 57.

While examining the adequacy of the original questions for describing the Asian person's pattern of symptom reporting, the experts identified that complaints about excessive gas as well as symptoms associated with gas (belching, fullness and bloating) were highly prevalent. The existing questions in the R3DQ were considered to be insufficient to elucidate the association between 
these symptoms and gas. It was also brought to attention that the term used to describe constipation in many of Asian languages (Chinese and Korean) was literally translated to mean difficulty in releasing stools. There were insufficient questions in R3DQ to explore the understanding and perception of this Asian concept on the term constipation. The additional questions developed to probe deeper into the characteristics of these symptoms are presented in the Supplementary Table 8 as R3DQ Q No. 14, 40, 56, 57 and 66.

The experts also reported that fullness and bloating were very common complaints among patients in whom they had made a clinical diagnosis of IBS. In some countries, the experts felt that bloating was more common than abdominal pain. It was further observed that many of these patients reported relief of their fullness or bloating with the passage of either stool or flatus. Therefore, options were added to elucidate the effects of passing stools and of passing flatus to R3DQ Q No. 14 and 66 (Supplementary Table 8).

The experts felt the need for a diagrammatic or pictorial representation to enable the interviewer to capture the desired information better in relation to the area related to location of abdominal pain; in R3DQ Q No. 17 and 68, patients were asked if they had experienced pain in the epigastrium or right hypochondrium. The experts observed that their patients had difficulty understanding the descriptions given on these 2 locations. Therefore, in these questions, a diagram of the abdomen divided into the standard nine quadrants was included.

Discrepancy was observed between verbal descriptors and patients' perceptions in relation to stool form. According to Rome or recently proposed Asian criteria, ${ }^{25}$ stool form is important to define constipation rather than frequency. Whereas Rome III criteria define Bristol types 1 or 2 stool forms as constipation, Asian criteria include type 3 stool as well to define constipation. ${ }^{25}$ Therefore, considering the importance of stool form to define constipation, a pictorial diagram of the Bristol stool scale was included to R3DQ Q No. 62 to overcome ambiguity arising from verbal descriptors. We extended this question to incorporate questions that would allow us to encompass patients' perceptions of their bowel habits, of what stool forms constitutes constipation, diarrhoea and a healthy bowel habit.

No change was made to the scoring algorithm; the frequency and severity scales in the $\mathrm{RD} 3 \mathrm{Q}$ were retained for all the questions. However, for some of our new questions we added options that seek to relate the timing of symptoms to meals. For example, we considered that the question relating to globus (R3DQ
Q No. 3) was ambiguous, as it could be interpreted to refer to dysphagia. Therefore, options were added to define the timing in relation to meals. We also added a scoring that takes into account the size of a meal for the question on post-prandial fullness (R3DQ Q No. 14).

\section{Phase 2: Results of Translation-Validation Study}

\section{The translated questionnaire}

The translated questionnaires had high concordance with the original English EAR3Q. Supplementary Tables 2-7 presents the reconciled version of the questionnaire in different Asian languages used in further validation studies. The understandability of the questionnaire by patients was not systematically investigated by cognitive debriefing. While administering the questionnaire during the validation study, many $\mathrm{HS}$ and the patients reported that questions were easily understood. However, most subjects reported that the questionnaire was quite lengthy. Time needed to complete the questionnaire was quite long as per data from 4 centers (median 35 [range 15-90] minutes).

\section{Demographic and clinical variables of the study subjects}

Table 1 presents data on demographic and clinical parameters of HS, patients with IBS, FD, and FC included in the validation studies.

\section{Result of validation of the translated questionnaires}

Table 2 presents the data on result of validation studies on translated questionnaires (sensitivity and specificity to pick-up clinical diagnoses and kappa values for test-retest agreement). Sensitivity and specificity of the questionnaires were high (60$100 \%$ ) to diagnose respective FGIDs (gold standard: clinical diagnoses) in most except Korean (27-67\%) and Indonesian (30-60\%) languages. Test- retest agreement (kappa) values of the translated questionnaires were variable. The Hindi, Telugu, and Chinese questionnaires had high concordance (kappa value 0.700 1.000 ) between the initial questionnaire-based diagnosis and that on 14th day. However, concordance for the Korean and Indonesian questionnaires varied between 0.100 and 0.500 and for the Thai questionnaire was 0.800 . Diagnostic performance of the Indonesian and Korean questionnaires was particularly low for FC, IBS, and FD (Table 2). In the Korean cohort, patients who had been categorized by their doctors to have FD showed particularly low concordance (only $3 / 11,27 \%$ ) with the outcome based on the patients' responses to the EAR3Q; 4/11 (36\%) were found 
Table 1. Number of Healthy Subjects, Patients With Irritable Bowel Syndrome, Functional Dyspepsia, and Functional Constipation Included in Validation Study and Their Demographic Parameters

\begin{tabular}{|c|c|c|c|c|}
\hline Demographic parameters & Healthy subjects & Irritable bowel syndrome & Functional constipation & Functional dyspepsia \\
\hline Hindi validation study & $\mathrm{n}=10$ & $\mathrm{n}=10$ & $\mathrm{n}=10$ & $\mathrm{n}=10$ \\
\hline Age (median [range], yr) & $26(21-56)$ & $33(17-53)$ & $45.5(18-66)$ & $49.5(26-65)$ \\
\hline Gender (M:F) & $4: 6$ & $8: 2$ & $3: 7$ & $7: 3$ \\
\hline Telegu validation study & $\mathrm{n}=10$ & $\mathrm{n}=11$ & $\mathrm{n}=6$ & $\mathrm{n}=8$ \\
\hline Age (median [range], yr) & $25.5(23-30)$ & $33.0(18-62)$ & $42(24-55)$ & $45.5(24-63)$ \\
\hline Gender (M:F) & $4: 6$ & 11:0 & $5: 1$ & $3: 5$ \\
\hline Chinese validation study & $\mathrm{n}=6$ & $\mathrm{n}=9$ & $\mathrm{n}=14$ & $\mathrm{n}=9$ \\
\hline Age (median [range], yr) & $26.5(24-47)$ & $46(24-65)$ & $41(20-59)$ & $42(23-65)$ \\
\hline Gender (M:F) & $2: 4$ & $3: 6$ & $8: 6$ & $4: 5$ \\
\hline Korean validation study & $\mathrm{n}=14$ & $\mathrm{n}=9$ & $\mathrm{n}=11$ & $\mathrm{n}=6$ \\
\hline Age (median [range], yr) & $36.5(24-52)$ & $37(27-48)$ & $33(31-65)$ & $38(21-58)$ \\
\hline Gender (M:F) & $5: 9$ & $6: 3$ & $4: 7$ & $0: 6$ \\
\hline Indonesian validation study & $\mathrm{n}=10$ & $\mathrm{n}=10$ & $\mathrm{n}=10$ & $\mathrm{n}=10$ \\
\hline Age (median [range], yr) & $32.8(21-62)$ & $46.9(22-72)$ & $43.1(26-63)$ & $45.2(22-67)$ \\
\hline Gender (M:F) & $5: 5$ & $7: 3$ & $1: 9$ & $1: 9$ \\
\hline Thai validation study & $\mathrm{n}=10$ & $\mathrm{n}=10$ & $\mathrm{n}=10$ & $\mathrm{n}=10$ \\
\hline Age (median [range], yr) & $44(26-66)$ & $45(24-63)$ & $46.5(37-65)$ & $53(14-62)$ \\
\hline Gender (M:F) & $3: 7$ & $2: 8$ & $3: 7$ & $1: 9$ \\
\hline Total number of subjects & 60 & 59 & 61 & 53 \\
\hline
\end{tabular}

to qualify IBS-criteria and another $2(18 \%)$ as functional bloating, while 5 (46\%) did not fulfil any specific FGID diagnosis. Some of the patients diagnosed as FC failed to meet the criteria on filling the questionnaire. In some languages, such as Hindi and Chinese, the questionnaire often uncovered symptoms of associated disorders such as FD among patients with IBS and FC and IBS among patients with FD both at the initial and at the 2-week follow-up visits (Table 2).

\section{Discussion}

In this study, a group of Asian FGID experts developed a socio-culturally adapted questionnaire (EAR3Q) for evaluating patients with FGIDs in Asia from R3DQ by consensus. Moreover, these experts, who are conversant with the target languages, translated and validated the EAR3Q into Chinese, Hindi-Telugu, Korean, Indonesian, and Thai following the guidelines formulated by the Rome Foundation. ${ }^{21,24}$ Culturally adapting the questionnaire has been recommended ${ }^{21}$ to achieve conceptually equivalent meaning and intent of the original instrument. There are cultural contexts and linguistic nuances in Asian languages that have potentially important impact on the interpretation of symptoms relating to the FGIDs.

We found that the nuances of some English wording were not appreciated by non-English speakers, eg, hurt to swallow, food or drinks get stuck after swallowing (stuck where?), and mushy stools. In most of the Asian languages, exact equivalent words are lacking for terms like heartburn and bloating. Moreover, there was overlap in the terms or words used to describe fullness, bloating and distension. For example, the Chinese word "zhang" is used to describe distension, but this word is also used to describe bloating and fullness.

In one study from China, when comparing between patients with FD alone and patients who were classified as FD-IBS overlap based on the Rome III criteria, post-prandial fullness predicted the presence of co-existing IBS. ${ }^{26}$ We suspect that some of these patients might not have experienced fullness, but instead were experiencing bloating, and could have been classified as IBS alone without FD overlap. In another study from Taiwan, about half of the patients initially classified as having FD, were found to have pure IBS, when it was confirmed that the sensations they had reported in the upper abdomen were relieved by defecation. ${ }^{27}$

In contrast to Western patients with IBS who localize pain more frequently to the lower abdomen, Asian patients often appear to localize their pain more frequently to the upper abdomen. ${ }^{28}$ In some Asian cultures, food and nutrition have traditionally been viewed as an important aspect of health and of illness. For example, "The Chinese do not draw any distinction between food 
Table 2. Diagnostic Performance of Translated Versions of Enhanced Asian Rome III Questionnaires

\begin{tabular}{|c|c|c|c|c|c|c|}
\hline Clinical di & nnostic category & $\begin{array}{l}\text { Concordance between clinical } \\
\text { and questionnaire-based }\end{array}$ & Sensitivity & Specificity & $\begin{array}{l}\text { Concordance of the } \\
\text { questionnaire between initial }\end{array}$ & $\begin{array}{c}\text { Kappa } \\
\text { (EAR3Q-based } \\
\text { diagnoses at initial }\end{array}$ \\
\hline Hindi & $\operatorname{HS}(\mathrm{n}=10)$ & 10 & $100 \%$ & $100 \%$ & 10 & 1.000 \\
\hline & $\operatorname{IBS}(\mathrm{n}=10)$ & 10 & $100 \%$ & & 10 & 1.000 \\
\hline & & $7(70 \%)$ had FD symptoms also & & & $7(70 \%)$ had FD symptoms also & \\
\hline & $\mathrm{FC}(\mathrm{n}=10)$ & 10 & $100 \%$ & & 10 & 1.000 \\
\hline & & $9(90 \%)$ had FD symptoms also & & & $9(90 \%)$ had FD symptoms also & \\
\hline & $\mathrm{FD}(\mathrm{n}=10)$ & 10 & $100 \%$ & & 10 & 1.000 \\
\hline & & $6(60 \%)$ had IBS symptoms also & & & 4 (40\%) had IBS symptoms also & \\
\hline Telugu & $\operatorname{HS}(\mathrm{n}=10)$ & 10 & $100 \%$ & $100 \%$ & 10 & 1.000 \\
\hline & $\operatorname{IBS}(\mathrm{n}=11)$ & 11 & $100 \%$ & & 11 & 1.000 \\
\hline & & $3(27 \%)$ had FD symptoms also & & & $2(18 \%)$ had FD symptoms also & \\
\hline & $\mathrm{FC}(\mathrm{n}=6)$ & 6 & $100 \%$ & & 6 & 1.000 \\
\hline & & $1(17 \%)$ had FD symptoms also & & & $1(17 \%)$ had FD symptoms also & \\
\hline & $\mathrm{FD}(\mathrm{n}=8)$ & 8 & $100 \%$ & & 8 & 1.000 \\
\hline Chinese & $\mathrm{HS}(\mathrm{n}=6)$ & 6 & $100 \%$ & $100 \%$ & 6 & 1.000 \\
\hline & $\operatorname{IBS}(\mathrm{n}=9)$ & 9 & $100 \%$ & & $7(77.8 \%)$ & 0.700 \\
\hline & $\mathrm{FC}(\mathrm{n}=9)$ & 9 & $100 \%$ & & 8 & 0.900 \\
\hline & & $1(11 \%)$ had FD symptoms also & & & & \\
\hline & $\mathrm{FD}(\mathrm{n}=14)$ & 14 & $100 \%$ & & 10 & 0.700 \\
\hline & & $5(35.7 \%)$ had FC symptoms also & & & $\begin{array}{l}2(20 \%) \text { had FC symptoms also } \\
1(10 \%) \text { had IBS symptoms also }\end{array}$ & \\
\hline Korean & $\mathrm{HS}(\mathrm{n}=14)$ & $13(93 \%)$ & $93 \%$ & $93 \%$ & 14 & 1.000 \\
\hline & $\operatorname{IBS}(\mathrm{n}=9)$ & 5 & $55.5 \%$ & & 4 & 0.400 \\
\hline & & $\begin{array}{l}1(11 \%) \text { had FD and } 1(11 \%) \text { had } \\
\text { functional bloating also and } 4 \text { did not } \\
\text { fulfil criteria for any specific FGIDs }\end{array}$ & & & $\begin{array}{l}1 \text { had FD and } 4 \text { did not fulfil criteria } \\
\text { for any specific FGIDs }\end{array}$ & \\
\hline & $\mathrm{FC}(\mathrm{n}=6)$ & 4 & $67 \%$ & & 3 & 0.500 \\
\hline & & $\begin{array}{l}2(33 \%) \text { had functional bloating also, } \\
1 \text { IBS and } 1 \text { did not fulfil criteria for } \\
\text { any specific FGIDs }\end{array}$ & & & $1(17 \%)$ had FD also and 3 had IBS & \\
\hline & $\mathrm{FD}(\mathrm{n}=11)$ & 3 & $27 \%$ & & 3 & 0.300 \\
\hline & & $\begin{array}{l}3(27 \%) \text { had IBS also, } 2 \text { functional } \\
\text { bloating, } 1 \text { IBS only and } 5 \text { did not } \\
\text { fulfil criteria for any specific FGIDs }\end{array}$ & & & $\begin{array}{l}3(27 \%) \text { had IBS also and } 2 \text { had } \\
\text { functional bloating, } 2 \text { had IBS, and } 4 \\
\text { did not fulfil criteria for any specific } \\
\text { FGIDs }\end{array}$ & \\
\hline Indonesian & $\mathrm{HS}(\mathrm{n}=10)$ & 9 & $90 \%$ & $90 \%$ & 9 & 0.900 \\
\hline & $\operatorname{IBS}(\mathrm{n}=10)$ & 6 & $60 \%$ & & 3 & 0.300 \\
\hline & & 3 had FD symptoms also & & & 2 had FD symptoms also & \\
\hline & $\mathrm{FC}(\mathrm{n}=10)$ & 3 & $30 \%$ & & 1 & 0.100 \\
\hline & & 2 had FD symptoms also & & & & \\
\hline & $\mathrm{FD}(\mathrm{n}=10)$ & 4 & $40 \%$ & & 4 & 0.400 \\
\hline & & 3 had IBS symptoms also & & & 1 had IBS & \\
\hline Thai & $\mathrm{HS}(\mathrm{n}=10)$ & 9 & $90 \%$ & $90 \%$ & 8 & 0.800 \\
\hline & $\operatorname{IBS}(\mathrm{n}=10)$ & 6 & $60 \%$ & & 8 & 0.800 \\
\hline & $\mathrm{FC}(\mathrm{n}=10)$ & 6 & $60 \%$ & & 8 & 0.800 \\
\hline & & 1 had IBS and 1 FD had symptoms also & & & & \\
\hline & $\mathrm{FD}(\mathrm{n}=10)$ & 8 & $80 \%$ & & 8 & 0.800 \\
\hline & & $1(10 \%)$ had functional bloating also & & & $1(10 \%)$ had functional bloating also & \\
\hline
\end{tabular}

EAR3Q, Enhanced Asian Rome III questionnaires; HS, healthy subject; IBS, irritable bowel syndrome; FC, functional constipation; FD, functional dyspepsia. 
and medicine." 29 It is conceivable that this cultural perspective could influence patients to perceive disturbed functions of the stomach as the origin of their symptoms.

We also observed that many of our patients in whom we make a clinical diagnosis of IBS may fail to fulfil Rome Criteria because they do not complain of pain. ${ }^{4}$ Across the Asian countries, we found that bloating was a dominant complaint among patients with IBS. ${ }^{3}$ It is possible that some of these patients may label their abdominal pain or discomfort as bloating. In a study by Gerson et al, ${ }^{30}$ significant positive correlations between the severity of abdominal pain and bloating were found across 7 countries (USA, Mexico, Canada, England, Italy, Israel, and India); this suggests that IBS subjects in these countries conceptualize pain and bloating as different but related concomitants of gastrointestinal disturbance.

The Rome Criteria indicate that hard stool refers to either Bristol type 1 or 2. However, in a study from South Korea, close to three-quarters of patients with IBS who had verbally reported passing hard stools, failed to meet this criteria. ${ }^{31} \mathrm{We}$ found some evidence that point to a relatively shorter colonic transit time among Asians compared with those reported in the West, both for healthy volunteers as well as subjects with constipation. ${ }^{3,25}$ To allow the patient's perspectives to be taken into consideration, we introduced a new approach of asking patients what type of stools were passed when they felt they were experiencing constipation, diarrhoea or normal bowel habits. Furthermore, we sought to explore the Asian peoples' concepts of constipation, by extending the questions on anal blockage by asking their perception of the stool characteristics when it was difficult to pass.

In validation study of the translated questionnaires, the diagnostic performance of Chinese, Hindi, and Telugu translations of the EAR3Q was high. Among all the translations, Korean and Indonesian translated EAR3Q often failed to diagnose several specific FGIDs although these questionnaires performed well in categorizing HS as healthy. This might be related to the fact that the physicians made the diagnosis without global evaluation for different subtypes of FGIDs, and therefore, in busy clinic, tended to overlook overlapping FGIDs. Other reasons may be related to recall bias by the patients on symptom duration and limitations of Rome III criteria. Moreover, small sample size in the present study might have over-estimated the frequency of overlap syndromes. In the Korean cohort, patients who had been categorized by their doctors to have FD showed particularly low concordance (only $3 / 11,27 \%$ ) with the outcome based on the patients' responses to the EAR3Q; 4 (36\%) were found to qualify as IBS and another $2(18 \%)$ as functional bloating, while 5 (46\%) did not fulfil any specific FGID diagnosis. This may reflect the failure of the doctors to enquire about bowel habits in the patients that they had diagnosed as FD, rather than failure of EAR3Q. In fact, this is one of the major diagnostic issue that we encounter in Asia where physicians frequently appear to mis-diagnose IBS as FD. ${ }^{3}$ This scenario is consistent with the observations by Lu et $\mathrm{al}^{27}$ that half of all patients presenting with upper abdominal symptoms who had received an initial diagnosis of FD were found on detailed questioning to have upper abdominal symptoms fulfilling IBS criteria. Similarly in the Indonesian cohort we found that only $40 \%$ of patients given a diagnosis of FD by their doctors fulfilled these criteria based on the questionnaire, while $30 \%$ achieved criteria for IBS in their questionnaire. Another poor performer was in FC where only $30 \%$ of patients who were thought by their doctors to have FC were able to satisfy Rome III criteria based on the questionnaire. One possible explanation is the discrepancy between the patients' perception which places importance to hardness of stool and incomplete evacuation, and the physicians' concept of constipation which emphasizes infrequent bowel movement. ${ }^{32}$ In a study from South Korea it was observed that close to three-quarters of patients who complained of hard stools failed to meet Rome criteria for hard stools. ${ }^{31}$ There are studies from Asia which point to shorter colonic transit times relative to those reported from the West. ${ }^{3}$ Thus, some of the discordance that we observed in our validation study may be due to important and relevant socio-cultural and even physiological differences between the East and the West.

We, for the first time, developed EAR3Q and successfully translated and validated it in several Asian languages. There was a good degree of understandability among the volunteers, a high sensitivity and specificity to diagnose various FGIDs and the test-retest reliability in Hindi-Telugu and Chinese questionnaire; these suggest that these translations were successful. Thai questionnaire also performed reasonably well. However, the Korean and Indonesian questionnaires were not found as valid and may require additional work to improve their test statistics. With the current trend of increasing number of drug trials in non-English speaking areas of world, importance of such translation cannot be over-estimated. The translated questionnaires in various Asian languages will be made available for use by other workers in the field. The busy clinicians may also use these questionnaires in clinical practice for global evaluation of patients with FGIDs, which will help them to particularly recognize the overlapping conditions that may have important bearing on treatment. 
A few limitations of the current study are worth mentioning. The questionnaire is expected to work better in younger and more educated people than older and less educated people. The HS included in all the validation studies except in Korea and Thailand were younger than the patients (Table 1). For less educated people, developing questionnaires with pictorial representations may be more useful. Some of the Asian languages have different dialect and pronunciations. People of rural areas may have somewhat variant understanding of some words than those in urban areas. For test-retest reliability, 2-week interval may be short and even may result in learning effect leading to different result. Small sample size in validation study is another limitation. It is however, under further validation in a large sample of patients with FGIDs in an Asian FGIDs survey, which will be published as separate papers. We believe, though not substantiated by the data, that these limitations are unlikely to be major limitations.

The questionnaire was able to identify overlapping FGIDs quite often that the clinicians had missed. This is not entirely unexpected as firstly, overlap syndromes are common, ${ }^{3,6,33-36}$ and secondly, physicians in a busy clinic may choose to focus only on the most bothersome symptom. Since overlap between various types of FGIDs is common ${ }^{3,6,33-36}$ and since this may have therapeutic and prognostic importance, ${ }^{37}$ the use of a diagnostic questionnaire may help busy clinicians to completely evaluate patients with FGIDs.

In conclusion, we have successfully developed a socio-culturally adapted questionnaire and translated it in several major Asian languages (Hindi-Telugu, Chinese, Korean, Indonesian and Thai). We believe that a culturally adapted questionnaire that takes into account the linguistic nuances and socio-cultural perspectives, is an important first step towards describing a true picture of FGID in Asia.

\section{Acknowledgements}

Authors thank the linguistic experts from Inforays, Hyderabad for their assistance in Indian translations. They also thank Dr Asha Misra and Tanushree from Gastrointestinal Pathophysiology and Motility Laboratory, Department of Gastroenterology, SGPGI, Lucknow, India for their help in Hindi translation and validation study. They also thank Dr Satawat Thongsawat for his assistance in Thai translations and thank Dr Kessarin Thanapirom for her assistance in data collection in Thai subjects. The authors wish to thank Abbott Products Operations AG and Janssen-Cilag Asia Pacific for unrestricted educational grants, and to acknowledge the support of the Rome Foundation and the Asian Neurogastroenterology and Motility Association.

\section{Supplemantary Materials}

Note: To access the supplementary table mentioned in this article, visit the online version of Journal of Neurogastroenterology and Motility at http://www.jnmjournal.org/, and at http://dx.doi. org/10.5056/jnm14045.

\section{References}

1. Longstreth GF, Thompson WG, Chey WD, Houghton LA, Mearin F, Spiller RC. Functional bowel disorders. Gastroenterology 2006;130:1480-1491.

2. Drossman DA. The functional gastrointestinal disorders and the Rome III process. Gastroenterology 2006;130:1377-1390.

3. Gwee KA, Lu CL, Ghoshal UC. Epidemiology of irritable bowel syndrome in Asia: something old, something new, something borrowed. J Gastroenterol Hepatol 2009;24:1601-1607.

4. Ghoshal UC, Abraham P, Bhatia SJ, et al. Comparison of Manning, Rome I, II, and III, and Asian diagnostic criteria: report of the multicentric Indian irritable bowel syndrome (MIIBS) study. Indian J Gastroenterol 2013;32:369-375.

5. Chang FY, Lu CL. Irritable bowel syndrome in the 21st century: perspectives from Asia or South-east Asia. J Gastroenterol Hepatol 2007;22:4-12.

6. Ghoshal UC, Singh R, Chang FY, et al. Epidemiology of uninvestigated and functional dyspepsia in Asia: facts and fiction. $\mathrm{J}$ Neurogastroenterol Motil 2011;17:235-244.

7. Barzkar M, Pourhoseingholi MA, Habibi M, et al. Uninvestigated dyspepsia and its related factors in an Iranian community. Saudi Med J 2009;30:397-402.

8. Chen LY, Ho KY, Phua KH. Normal bowel habits and prevalence of functional bowel disorders in Singaporean adults - findings from a community based study in Bishan. Community medicine GI study group. Singapore Med J 2000;41:255-258.

9. Ho KY, Kang JY, Seow A. Prevalence of gastrointestinal symptoms in a multiracial Asian population, with particular reference to reflux-type symptoms. Am J Gastroenterol 1998;93:1816-1822.

10. Tan YM, Goh KL, Muhidayah R, Ooi CL, Salem O. Prevalence of irritable bowel syndrome in young adult Malaysians: a survey among medical students. J Gastroenterol Hepatol 2003;18:1412-1416.

11. Pan G, Lu S, Ke M, Han S, Guo H, Fang X. Epidemiologic study of the irritable bowel syndrome in Beijing: stratified randomized study by cluster sampling. Chin Med J 2000;113:35-39.

12. Makharia GK, Verma AK, Amarchand R, et al. Prevalence of irritable bowel syndrome: a community based study from northern India. J Neurogastroenterol Motil 2011;17:82-87.

13. Sperber AD, Drossman DA, Quigley EM. The global perspective on irritable bowel syndrome: a Rome foundation-world gastroenterology organisation symposium. Am J Gastroenterol 2012;107:16021609 
14. Sperber AD. The challenge of cross-cultural, multi-national research: potential benefits in the functional gastrointestinal disorders. Neurogastroenterol Motil 2009;21:351-360.

15. Schmulson M, Corazziari E, Ghoshal UC, et al. A four-country comparison of healthcare systems, implementation of diagnostic criteria, and treatment availability for functional gastrointestinal disorders: a report of the Rome foundation working team on cross-cultural multinational research. Neurogastroenterol Motil 2014;26: 1368-1385.

16. Sperber AD. Translation and validation of study instruments for cross-cultural research. Gastroenterology 2004;126(suppl 1):S124S128.

17. Longstreth GF, Thompson WG, Chey WD, Houghton LA, Mearin F, Spiller RC. Functional bowel disorders. Gastroenterology 2006;130:1480-1491.

18. Tack J, Talley NJ, Camilleri M, et al. Functional gastroduodenal disorders. Gastroenterology 2006;130:1466-1479.

19. Hu WH, Wong WM, Lam CL, et al. Anxiety but not depression determines health care-seeking behaviour in Chinese patients with dyspepsia and irritable bowel syndrome: a population-based study. Aliment Pharmacol Ther 2002;16:2081-2088.

20. Ghoshal UC, Abraham P, Bhatt C, et al. Epidemiological and clinical profile of irritable bowel syndrome in India: report of the Indian society of gastroenterology task force. Indian J Gastroenterol 2008; 27:22-28.

21. Sperber AD, Gwee KA, Hungin AP, et al. Conducting multinational, cross-cultural research in the functional gastrointestinal disorders: issues and recommendations. A Rome foundation working team report. Aliment Pharmacol Ther 2014;40:1094-1102.

22. Fitzpatrick R, Davey C, Buxton MJ, Jones DR. Evaluating patient-based outcome measures for use in clinical trials. Health Technol Assess 1998;2:i-iv, 1-74.

23. Rome III diagnostic questionnaire for the adult functional GI disorders (including alarm questions) and scoring algorithm. Available from URL: http://www.romecriteria.org/pdfs/AdultFunctGIQ.pdf (accessed 1 Dec 2014).

24. Rome Foundation guideline. Available from URL: http://www.romecriteria.org/translations (accessed 1 Dec 2014).

25. Gwee KA, Bak YT, Ghoshal UC, et al. Asian consensus on irritable bowel syndrome. J Gastroenterol Hepatol 2010;25:1189-1205.

26. Wang A, Liao XH, Xiong L, et al. Clinical overlap between functional dyspepsia and irritable bowel syndrome based on Rome III criteria. BMC Gastroenterology 2008;8:43.

27. Lu CL, Lang HC, Chang FY, et al. Prevalence and health/social impacts of functional dyspepsia in Taiwan: a study based on the Rome criteria questionnaire survey assisted by endoscopic exclusion among a physical check-up population. Scand J Gastroenterol 2005; 40:402-411.

28. Gwee KA. Irritable bowel syndrome in developing countries - a disorder of civilization or colonization? Neurogastroenterol Motil 2005; 17:317-324.

29. Yutang L. The importance of living. New York: William Morrow \& Company, Inc 1998.

30. Gerson CD, Gerson MJ, Awad RA, et al. Irritable bowel syndrome: an international study of symptoms in eight countries. Eur J Gastroenterol Hepatol 2008;20:659-667.

31. Park JM, Choi MG, Cho YK, et al. Functional gastrointestinal disorders diagnosed by Rome III questionnaire in Korea. J Neurogastroenterol Motil 2011;17:279-286.

32. Gwee KA, Ghoshal UC, Gonlachanvit S, et al. Primary care management of chronic constipation in Asia: The ANMA chronic constipation tool. J Neurogastroenterol Motil 2013;19:149-160.

33. Nakajima S, Takahashi K, Sato J, et al. Spectra of functional gastrointestinal disorders diagnosed by Rome III integrative questionnaire in a Japanese outpatient office and the impact of overlapping. J Gastroenterol Hepatol 2010;25(suppl 1):S138-S143.

34. Kaji M, Fujiwara $Y$, Shiba M, et al. Prevalence of overlaps between GERD, FD and IBS and impact on health-related quality of life. J Gastroenterol Hepatol 2010;25:1151-1156.

35. Park H. Functional gastrointestinal disorders and overlap syndrome in Korea. J Gastroenterol Hepatol 2011;26(suppl 3):12-14.

36. Yarandi SS, Nasseri-Moghaddam S, Mostajabi P, Malekzadeh R. Overlapping gastroesophageal reflux disease and irritable bowel syndrome: increased dysfunctional symptoms. World J Gastroenterol 2010;16:1232-1238.

37. Neumann H, Monkemuller K, Kandulski A, Malfertheiner P. Dyspepsia and IBS symptoms in patients with NERD, ERD and Barrett's esophagus. Dig Dis 2008;26:243-247. 